\title{
Prevalence of Sexual Dysfunctions and their Associated Factors in Pregnant Women in an Outpatient Prenatal Care Clinic
}

\section{Prevalência de disfunções sexuais e seus fatores associados em gestantes de uma clínica de pré-natal}

\author{
Julianna Azevedo Guendler ${ }^{1}$ Leila Katz ${ }^{1}$ Maria Eduarda Duarte Mello Flamini ${ }^{2}$ Andrea Lemos ${ }^{3}$
}

Melania Maria Amorim ${ }^{1}$

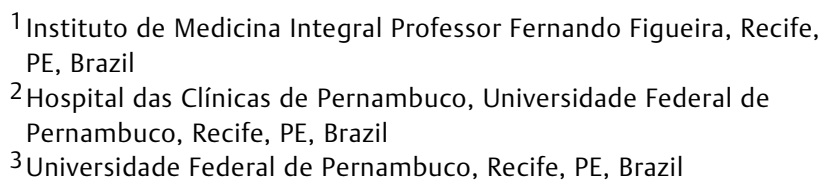

Address for correspondence Julianna de Azevedo Guendler, Master, Rua Professor Eduardo Wanderley Filho, 293/101, 51020-170, Recife, PE, Brazil (e-mail: jujuguendler@gmail.com).

Rev Bras Ginecol Obstet 2019;41:555-563.

\begin{abstract}
\section{Keywords}

- sexual dysfunction

- sexuality

- pregnancy

- women's health

- prevalence

Objective To determine the prevalence of sexual dysfunction and its associated factors in pregnant women.

Methods A descriptive, cross-sectional study including 262 pregnant women aged 18 years or older with gestational age between 10 and 35 weeks. Women with urinary tract infections and conditions of gestational risk were excluded. The Pregnancy Sexual Response Inventory (PSRI) questionnaire was used. We performed a univariate descriptive analysis, and comparisons between the mean values of the sexual function domains were made using the Student $t$-test. The chi-squared test was used to determine the association between the independent and dependent variables. The prevalence ratios, with their respective $95 \%$ confidence intervals, were also estimated, and a multivariate analysis was performed.

Results A total of $64.9 \%$ of women reported a decrease in the frequency of sexual activity during pregnancy. Slightly more than half of the women (50.8\%) were satisfied, and arousal was reported as excellent/good by $30.5 \%$ of them. The frequency of sexual difficulties/dysfunctions increased with pregnancy, rising from $5.7 \%$ to $58.8 \%$, and pain during sexual intercourse was reported by $45.8 \%$ of them. Having higher education degree decreased the chance of being sexually dissatisfied by $50 \%$. The total PSRI score showed a significant decrease from the prepregnancy period (mean score $=89.8$, "excellent") to the pregnancy period (mean score $=59.2$, "good").

Conclusion The mean sexual function score during pregnancy was classified as good, although most pregnant women reported at least one type of alteration in the sexual
\end{abstract}

(D) Julianna Azevedo Guendler's ORCID is https://orcid.org/00000002-2712-2599.

received

March 22, 2019

accepted

June 17, 2019
DOI https://doi.org/

10.1055/s-0039-1695021. ISSN 0100-7203.
Copyright $\odot 2019$ by Thieme Revinter

Publicações Ltda, Rio de Janeiro, Brazil
License terms

(c) (1) 


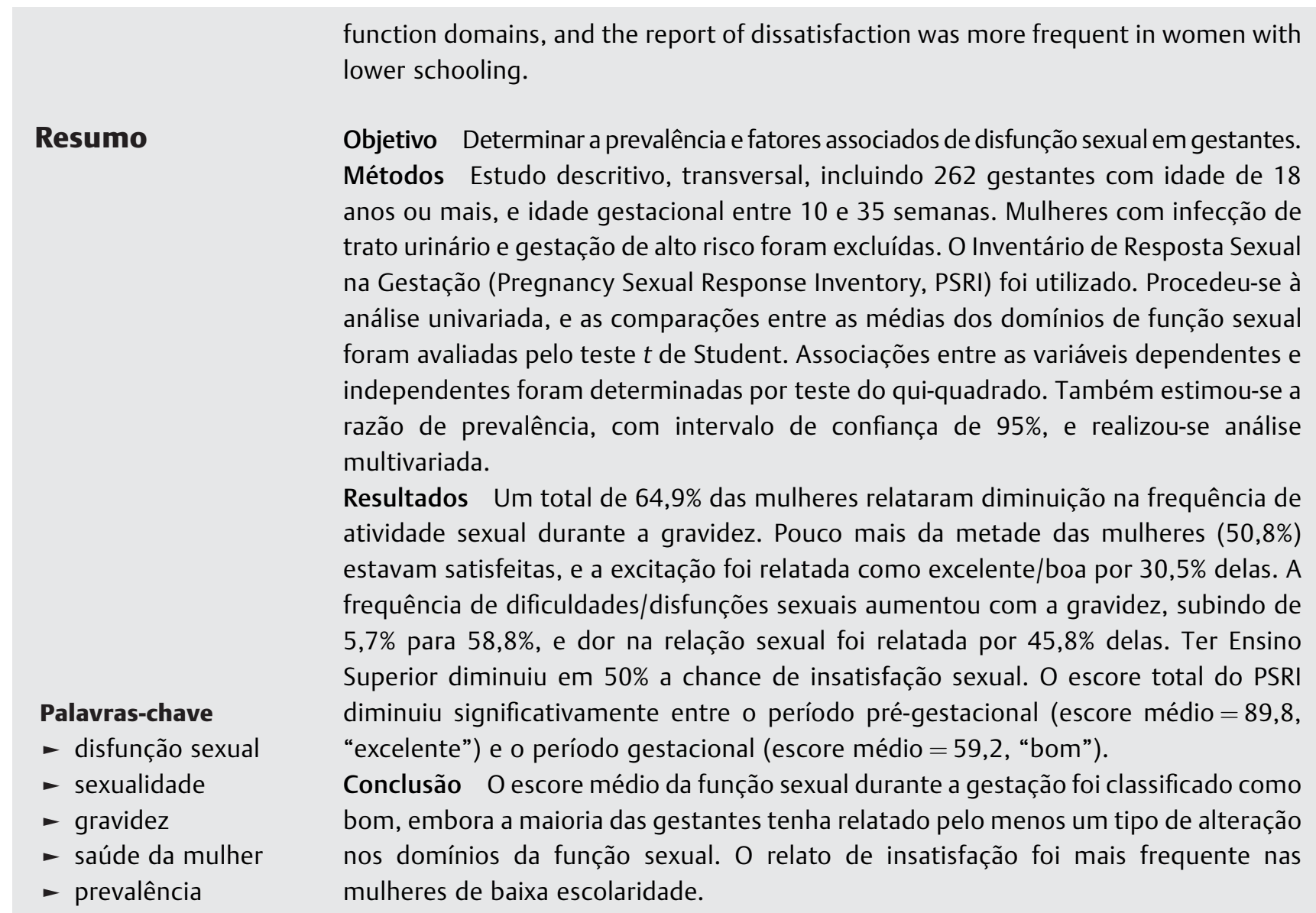

\section{Introduction}

Pregnancy is a special event in a woman's life, and it is accompanied by major physiological, psychologic and social changes that have repercussions on self-image, interpersonal relationships and sexuality. ${ }^{1-3}$ The process of constructing motherhood involves a great deal of anxiety and primal fears, such as doubts about labor, about the ability to generate a healthy baby, and about the new relationships with the arrival of a new member in the family. In addition to this process, there are still adaptations to the new body, and physical discomfort and fatigue, which combined with cultural factors, can influence the sexual life of the couple. . $^{2,4}$

According to a Brazilian systematic review, ${ }^{6}$ the prevalence of sexual dysfunction during pregnancy ranged from $38.9 \%$ to $73.3 \%$, depending on the trimester of the pregnancy, when the assessment was conducted and associated diseases. ${ }^{6}$ As the pregnancy progresses, there is a tendency towards a decline in sexual activity. This deterioration in sexual function occurs not only in relation to the frequency of sexual intercourse, but also regarding the various domains of sexuality (desire, arousal, lubrication, orgasm, satisfaction and dyspareunia). ${ }^{7-9}$

Female sexual dysfunctions clearly appear to be multifaceted, and have been associated with individual variables. Some studies point to factors related to sexual dysfunction during pregnancy, such as: maternal age; schooling; number of children; pregnancy planning; body image; satisfaction with the couple's relationship; depression; and anxiety, among others. ${ }^{2,4,10}$ However, there is no established evidence of the real influence of most of these factors on sexual function.

Prepregnancy sexuality plays an important role in maintaining sexuality during pregnancy. ${ }^{11}$ In this context, the assessment of the sexual function of a couple since the beginning of the pregnancy can be useful so they maintain a healthy sexual activity, reduce and alleviate any anxiety they may have, and so that the woman experiences less discomfort related to sexual function during pregnancy.

In addition, it is essential to know the main changes resulting from pregnancy in order to apply measures to minimize the impact of sexual dysfunction on the relationship of the couple. The search for more epidemiological data evaluating the prevalence of sexuality dysfunctions before and during pregnancy and their associated factors is important to measure the magnitude of this problem.

Thus, the objective of the present study was to determine the prevalence of sexual dysfunction in pregnant women followed at the prenatal care clinic of a reference hospital, to compare this prevalence with the period before pregnancy and to analyze the factors associated with sexual dissatisfaction, using a questionnaire validated for pregnant women. 


\section{Methods}

This cross-sectional study was approved by the Ethics in Research Committee of Instituto de Medicina Integral Professor Fernando Figueira (IMIP), under registration number 43913115.4.0000.5201. The study was conducted at the outpatient prenatal care clinic in a hospital located in the city of Recife, in the state of Pernambuco, Brazil.

The sample size was calculated using the public domain software Open Epi, version 3.01, predicting a prevalence of sexual dysfunction of $67.7 \%$, assuming a $5 \%$ margin of error and a $90 \%$ confidence level. ${ }^{12}$ Thus, 240 pregnant women would be necessary, but considering the possible losses and different prevalence rates of female sexual dysfunction in our population, the sample was increased by $10 \%$, totalizing 264 pregnant women.

All pregnant women waiting for prenatal consultations between July and October 2015 were invited to participate in the study. Pregnant women aged $\geq 18$ years, with gestational age between 10 and 35 weeks, were included, and women presenting urinary tract infection or medical or obstetric conditions for which intercourse was not advisable (placenta previa, prenatal hemorrhage or treatment for preterm birth) were excluded.

The selection of the patients occurred after detailed explanations about the research were provided, and after the women signed informed consent forms. The interviews were performed prior to the consultations by a trained evaluator in a private room, ensuring confidentiality.

The Portuguese version of the Pregnancy Sexual Response Inventory (PSRI) questionnaire was used. ${ }^{13}$ This questionnaire contains 38 items: 12 are related to sociodemographic characteristics, and 26 cover sexual behavior activity. The first part of the questionnaire consists of maternal age, gestational age, partnership status, socioeconomic status (level of schooling and occupation), religion, number of children, use of condoms, pregnancy planning, smoking and alcohol use or drug abuse. The second part of the questionnaire consists of 10 domains, and 8 of them are related to the women's feelings, and 2 are related to the women's perceptions of their partners' sexual interest.

The eight domains of women's feelings include: a) Frequency: a three-item scale that assesses the frequency of sexual intercourse relating to pregnancy; b) Desire: a three-item scale that assesses the frequency of desire before and during pregnancy, and the frequency of participation in sexual activity; c) Arousal: a three-item scale that assesses the quality of sexual activity before and during pregnancy; d) Orgasm: a three-item scale that measures the frequency of orgasm before and during pregnancy; e) Satisfaction: a three-item scale that assesses the enjoyment of sex life before and during pregnancy; f) Dyspareunia: a two-item scale that assesses pain during sexual intercourse before and during pregnancy; g) Intercourse initiation: a three-item scale that assesses the beginning of the participation in sexual activity before and during pregnancy; and h) Female difficulties: a two-item scale that assesses any female sexual difficulties before and during pregnancy. The women's perception of their partners' sexuality includes: i) Male sexual satisfaction: a three-item scale that evaluates the female view of male satisfaction before and during pregnancy; and j) Male sexual difficulties: a two-item scale that assesses the female view of male sexual difficulties before and during pregnancy.

The calculation of the specific score for each domain and the final composite score of the PSRI domains were established by Rudge et al. ${ }^{13}$ In grading the PSRI responses, " 0 " is considered the worst, and " 100 ", the best. The final score is categorized into quartiles by sexual response, as follows: 0 to 25 = "very bad"; 25 to 50 = "bad"; 50 to $75=$ "good"; and 75 to $100=$ "excelent". 14

A Microsoft Excel (Microsoft, Redmond, WA, US) spreadsheet was used for the development of the database, with double entry for validation. The Stata software (StataCorp LLC, College Station, TX, US), version 12.1, was used for the statistical analyses. A univariate descriptive analysis of the variables (distribution of relative and absolute frequencies, as well as measures of central tendency and dispersion) was performed. Comparisons between the mean values of the sexual function domains were made using the Student $t$-test. The chi-squared test was used to determine the association between the independent or predictive variables (sociodemographic characteristics) and the dependent variable (sexual dissatisfaction). The prevalence ratios (PRs) with their respective 95\% confidence intervals (95\%Cls) were also estimated. A significance level of $5 \%$ was considered to perform the statistical tests. All $p$ values considered were two-tailed. A standard risk of 1.0 was assigned to the reference category. Subsequently, a stepwise logistic regression was performed.

\section{Results}

Out of a total of 276 pregnant women accessed for eligibility, 3 were excluded for being younger than 18 years of age, 7 because they did not have gestational age between 10 and 35 weeks, and 2 because they reported having placenta previa. In addition to the exclusions, two patients reported being busy and refused to participate (-Fig. 1). Therefore, 262 pregnant women in the age range of 18 to 43 years, with a mean age of 27.6 (standard deviation [SD]: 6.0) and a mean gestational age of 25.5 weeks (SD: 7.1), composed the sample. A total of $7.2 \%$ of them were in the first trimester, $48.1 \%$ were in the second, and $44.7 \%$ were in the third trimester.

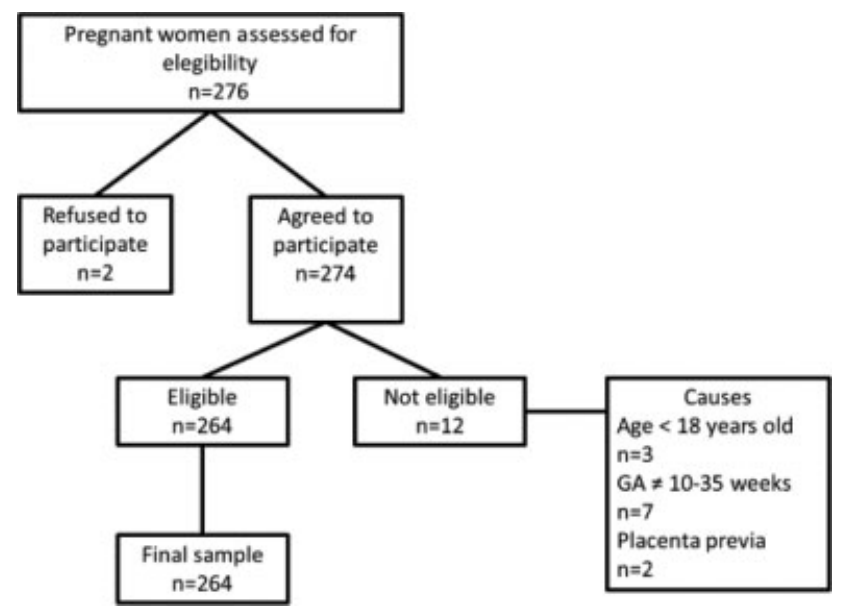

Fig. 1 Flowchart of the enrollment of the participants. 
There was a predominance of women who were married (formally or informally, 82.8\%), with high school degrees (61.1\%), and who were employed (47.7\%). As for religion, 43.1\% were Protestant and $40.8 \%$ were Catholic. In relation to the number of children, $53.4 \%$ were primigravidae, and only $18.7 \%$ had 2 or more children. A total of $74.0 \%$ reported not using condoms, 96.2\% did not use alcohol, 99.2\% did not smoke, and none reported using illicit drugs. Most of the pregnant women (57.6\%) did not plan the current pregnancy (-Table 1).

Table 1 Frequency distribution of the demographic variables

\begin{tabular}{|l|l|}
\hline Variable & $\mathbf{n}(\%)$ \\
\hline Partnership status (N=262) & \\
\hline Formal marriage/Common-law marriage & $217(82.8)$ \\
\hline Single & $39(14.9)$ \\
\hline Other & $6(2.3)$ \\
\hline Level of schooling ( $=262)$ & \\
\hline Elementary School & $35(13.4)$ \\
\hline High School & $160(61.1)$ \\
\hline College/University & $67(25.6)$ \\
\hline Religion (N=262) & \\
\hline Catholic & $107(40.8)$ \\
\hline Protestants & $113(43.1)$ \\
\hline Other/No religion & $42(16.0)$ \\
\hline Occupation (N=262) & \\
\hline Housewife & $67(25.6)$ \\
\hline Employed & $125(47.7)$ \\
\hline Not employed & $70(26.7)$ \\
\hline Number of children $(N=262)$ & \\
\hline None & $140(53.4)$ \\
\hline 1 & $73(27.9)$ \\
\hline$\geq 2$ & $49(18.7)$ \\
\hline Smoking during pregnancy $(N=262)$ & \\
\hline Yes & $2(0.8)$ \\
\hline No & $260(99.2)$ \\
\hline Use of alcohol $(N=262)$ & \\
\hline Often/Very often & $1(0.4)$ \\
\hline Sometimes & $9(3.4)$ \\
\hline No & $252(96.2)$ \\
\hline Drug abuse (N=262) & \\
\hline No & $262(14.95 .1)$ \\
\hline Pregnancy planning (N=262) & \\
\hline Yes & $111(42.4)$ \\
\hline No & \\
\hline Condom use ( $N=262)$ & \\
\hline Yes & \\
\hline No & \\
\hline
\end{tabular}

A decrease in sexual activity was reported by $64.9 \%$ of the women during pregnancy, while only $7.6 \%$ reported an increase in frequency. Sexual satisfaction during pregnancy decreased in $41.6 \%$ of the women. A total of $92 \%$ reported that they were sexually satisfied before pregnancy, and $50.8 \%$, during pregnancy. In the domain of sexual desire, most participants reported that it depended on the occasion or disposition (-Table 2). Regarding the arousal domain, $80.9 \%$ of the sample classified it as excellent/good before pregnancy, decreasing to $30.5 \%$ during pregnancy, while $0.4 \%$ reported it as bad/terrible before pregnancy, increasing to $23.3 \%$ during it. When asked if they had orgasms with sexual intercourse, $90.1 \%$ answered that they always/usually had them before pregnancy, while only $54.6 \%$ always/usually had orgasms during pregnancy (-Table 2). Dyspareunia was reported by $11.1 \%$ of the women before pregnancy, and by $45.8 \%$ during pregnancy. In the sample, $90.1 \%$ of the pregnant women reported that the initiation of sexual intercourse was spontaneous before pregnancy, reducing to $68.7 \%$ after pregnancy. The frequency of sexual difficulties/dysfunctions also increased with pregnancy, rising from $5.7 \%$ to $58.7 \%$ (-Table 2). Finally, two domains of the questionnaire were about the perception that the pregnant women had regarding their partners' sexuality. They attributed scores from 0 to 10 regarding their partners' sexual satisfaction and the sexual difficulties they might have. Before pregnancy, $87.4 \%$ of the sample gave scores from 8 to 10 , whereas during pregnancy only $33.2 \%$ gave those same scores. Before pregnancy, only $1.1 \%$ reported that the partner had some sexual difficulty, but this rate increased to $10.3 \%$ during pregnancy (-Table 2 ).

In relation to the association of sexual dissatisfaction with the independent variables (maternal age, gestational age, partnership status, schooling, religion, occupational status, number of children, condom use, pregnancy planning, smoking, and alcohol or drug use), the only variable associated with sexual dissatisfaction was schooling. Having a higher education degree reduced the chance of being sexually dissatisfied by $50 \%$ (PR: 0.69 ; $95 \%$ CI: $0.49-0.98 ; p=0.02$ ), which was statistically significant. The other variables did not present a statistically significant association (-Table 3). After the multiple logistic regression analysis, higher levels of schooling remained associated with a lower chance of sexual dissatisfaction (Prevalence Ratio [PR] $=0.52 ; 95 \% \mathrm{CI}$ : 0.29-0.92; $p=0.02$ ).

The specific and total scores for each domain before and during pregnancy were calculated. During pregnancy, in every PSRI domain, the specific scores were lower than before pregnancy $(p<0.001)$ ( - Table 4). The total PSRI score evaluated showed a significant decrease from the pre-pregnancy period (mean score $=89.8$, "excellent") to the pregnancy period (mean score $=59.2$, "good").

\section{Discussion}

The findings of the present study indicate that along with the decrease in frequency and sexual satisfaction on the part of the pregnant women, all areas of sexuality (desire, arousal, orgasm and pain) suffer changes during pregnancy. The results also showed that a high level of schooling decreased 
Table 2 Frequency distribution of the sexual characteristics of the pregnant women and their partners before and during pregnancy

\begin{tabular}{|c|c|c|c|c|c|}
\hline \multicolumn{2}{|l|}{ Variables } & \multicolumn{2}{|c|}{$\begin{array}{l}\text { Before } \\
\text { pregnancy }\end{array}$} & \multicolumn{2}{|c|}{$\begin{array}{l}\text { During } \\
\text { pregnancy }\end{array}$} \\
\hline & & \multirow{2}{*}{$\frac{N}{-}$} & \multirow{2}{*}{$\frac{\%}{-}$} & \multirow{2}{*}{$\frac{\mathrm{N}}{170}$} & \multirow{2}{*}{$\frac{\%}{64.9}$} \\
\hline Frequency & Decreased & & & & \\
\hline & Remained the same & - & - & 72 & 27.5 \\
\hline & Increased & - & - & 20 & 7.6 \\
\hline \multirow[t]{3}{*}{ Satisfaction } & No & 5 & 1.9 & 58 & 22.1 \\
\hline & More or less & 15 & 5.7 & 71 & 27.1 \\
\hline & Yes & 242 & 92.4 & 133 & 50.8 \\
\hline \multirow[t]{3}{*}{ Desire } & A few times a week & 78 & 27.5 & 54 & 20.6 \\
\hline & Once a day & 39 & 14.9 & 19 & 7.3 \\
\hline & It depends on the occasion/disposition & 151 & 57.6 & 189 & 72.1 \\
\hline \multirow[t]{3}{*}{ Arousal } & Excelent/good & 212 & 80.9 & 80 & 30.5 \\
\hline & Regular & 49 & 18.7 & 121 & 46.2 \\
\hline & Bad/terrible & 1 & 0.4 & 61 & 23.3 \\
\hline \multirow[t]{3}{*}{ Orgasm } & No & 233 & 88.9 & 120 & 45.8 \\
\hline & Sometimes & 21 & 8.0 & 66 & 25.2 \\
\hline & Always/Usually & 236 & 90.1 & 143 & 54.6 \\
\hline \multirow[t]{2}{*}{ Dyspareunia } & Yes & 29 & 11.1 & 142 & 54.2 \\
\hline & No & 233 & 88.9 & 120 & 45.8 \\
\hline \multirow[t]{3}{*}{ Intercourse initiation } & Forced without desire & 1 & 0.4 & 24 & 9.2 \\
\hline & Initiated by the partner & 25 & 9.5 & 82 & 22.1 \\
\hline & Spontaneous/Spontaneous with stimulus & 236 & 90.1 & 180 & 68.7 \\
\hline Female difficulties & Yes & 15 & 5.7 & 154 & 58.8 \\
\hline \multirow[t]{3}{*}{ Male sexual satisfaction } & Grades $0-3$ & 3 & 1.1 & 80 & 30.5 \\
\hline & Grades 4-7 & 30 & 11.5 & 95 & 36.3 \\
\hline & Grades 8-10 & 229 & 87.4 & 87 & 33.2 \\
\hline \multirow[t]{2}{*}{ Male sexual difficulties } & Yes & 3 & 1.1 & 27 & 10.3 \\
\hline & No & 259 & 98.9 & 235 & 89.7 \\
\hline
\end{tabular}

the chance of a woman being sexually dissatisfied during pregnancy by $50 \%$.

The sample of the present study consisted mostly of women who: were primigravidae; married; Catholic and Protestant in similar rates; employed; had high-school degrees; did not use alcohol or illicit drugs during pregnancy; did not have the habit of using condoms; and reported that the pregnancy was not planned. This population is similar to that found in the Brazilian study ${ }^{14}$ that created the score for the PSRI, except in relation to the level of schooling, which had a more homogenous distribution between those with elementary and high-school levels of schooling. ${ }^{14}$

There was a reduction in the frequency of sexual intercourse during pregnancy, a finding that was already observed in previous studies. The change in sexuality can be guided by myths, taboos, religious and sociocultural issues, and can also be justified by the fear of harming the fetus, discomfort with certain positions or with the weight of the gestational abdomen, fear of anticipating labor, pain during the sexual act, among other factors. ${ }^{9,15,16}$

Sexual satisfaction correlates, among other things, with the sense of happiness resulting from pregnancy, with the sense of her own attractiveness on the part of the pregnant woman, and with the experience of orgasm. ${ }^{17}$ Although the majority of the sample reported that they were satisfied with their sexual lives, both before and during pregnancy, there was a decrease in sexual satisfaction in a large number of women during pregnancy.

In the present study, we observed that the sexual desire also decreased during pregnancy. Similar results were found in a study ${ }^{16}$ with 150 Turkish pregnant women, in which $68.7 \%$ of them had decreased desire in the third trimester. ${ }^{16}$ In Brazil, in a study ${ }^{18}$ with pregnant women with diabetes, $80 \%$ of them reported not thinking spontaneously about sex, 
Table 3 Association between the independent variables and sexual dissatisfaction

\begin{tabular}{|c|c|c|c|c|c|}
\hline Variable & Dissatisfaction $(\mathrm{N}=129)$ & Satisfaction $(\mathrm{N}=133)$ & PR & $95 \% \mathrm{Cl}$ & $p$-value \\
\hline Maternal age in year - mean (SD) & $27.2(6.1)$ & $28.0(5.9)$ & - & - & 0.31 \\
\hline \multicolumn{6}{|l|}{ Age $>27$ years } \\
\hline Yes & $56(46.3)$ & $65(53.3)$ & 0.89 & $0.69-1.14$ & 0.37 \\
\hline No & $73(51.8)$ & $68(48.2)$ & & & \\
\hline Gestational age in weeks - mean (SD) & $26.1(7.1)$ & $24.8(6.9)$ & - & - & 0.13 \\
\hline \multicolumn{6}{|l|}{ Gestational age $>25$ years $(\%)$} \\
\hline Yes & $77(53.1)$ & $68(46.9)$ & 1.19 & $0.92-1.54$ & 0.16 \\
\hline No & $52(44.4)$ & $65(55.6)$ & & & \\
\hline \multicolumn{6}{|l|}{ Single - n (\%) } \\
\hline Yes & $229(48.9)$ & $23(58.1)$ & 0.99 & $0.71-1.37$ & 0.95 \\
\hline No & $107(49.3)$ & $110(50.7)$ & & & \\
\hline \multicolumn{6}{|l|}{ College/University - n (\%) } \\
\hline Yes & $25(37.3)$ & $42(62.7)$ & 0.69 & $0.49-0.98$ & 0.02 \\
\hline No & $104(53.3)$ & $91(46.7)$ & & & \\
\hline \multicolumn{6}{|l|}{ Protestants - n (\%) } \\
\hline Yes & $57(50.4)$ & $56(49.6)$ & 1.04 & $0.81-1.33$ & 0.73 \\
\hline No & $72(48.3)$ & $77(51.7)$ & & & \\
\hline \multicolumn{6}{|l|}{ Not employed - n (\%) } \\
\hline Yes & $34(50.7)$ & $33(49.3)$ & 1.04 & $0.79-1.37$ & 0.77 \\
\hline No & $95(48.7)$ & $100(51.3)$ & & & \\
\hline \multicolumn{6}{|l|}{ Children - n (\%) } \\
\hline Yes & $66(54.1)$ & $56(45.9)$ & 1.2 & $0.94-1.53$ & 0.14 \\
\hline No & $63(45.0)$ & $77(55.0)$ & & & \\
\hline \multicolumn{6}{|l|}{ Smoking - n (\%) } \\
\hline Yes & $1(50.0)$ & $1(50.0)$ & 1.01 & $0.25-4.08$ & $0.74^{*}$ \\
\hline No & $128(49.2)$ & $132(50.8)$ & & & \\
\hline \multicolumn{6}{|l|}{ Alcohol use - n (\%) } \\
\hline Yes & $6(60.0)$ & $4(40.0)$ & 1.22 & $0.72-2.07$ & $0.35^{*}$ \\
\hline No & $123(48.8)$ & $129(51.2)$ & & & \\
\hline \multicolumn{6}{|l|}{ Planned pregnancy - n (\%) } \\
\hline Yes & $79(52.3)$ & $72(47.7)$ & 1.16 & $0.89-1.49$ & 0.24 \\
\hline No & $50(45.0)$ & $61(55.0)$ & & & \\
\hline \multicolumn{6}{|l|}{ Condom use - $\mathrm{n}(\%)$} \\
\hline Yes & $20(51.3)$ & $19(48.7)$ & 1.04 & $0.75-1.46$ & 0.78 \\
\hline No & 109 (48.9) & $114(51.1)$ & & & \\
\hline
\end{tabular}

Notes: *Fisher test. No women reported drug abuse.

Abbreviations: 95\% Cl, 95\% confidence interval; PR, prevalence ratio; SD, standard deviation.

probably because the high-risk pregnancy could generate tension, compromising sexual desire. ${ }^{18,19}$

Regarding the arousal domain, a decrease in arousal with pregnancy was observed. Similar findings were observed in a cross-sectional study ${ }^{20}$ with 181 non-pregnant women and 177 pregnant women, in which the overall sexual dysfunction rate was of $31.7 \%$, and it was more prevalent in pregnant women (40.4\%) than in non-pregnant women (23.3\%), with a significant difference between them in the score of the arousal domain $(p=0.003) .^{20}$

The criteria that characterize sexual dysfunction in the Diagnostic and Statistical Manual of Mental Disorders, Fourth Edition (DSM-IV) included low sexual desire, sexual arousal disorder, orgasmic disorder and sexual pain disorder. However, 
Table 4 Composite and specific scores of the Pregnancy Sexual Response Inventory before and during pregnancy

\begin{tabular}{|l|l|l|l|}
\hline & $\begin{array}{l}\text { Before } \\
\text { pregnancy } \\
(\mathbf{N}=262)\end{array}$ & $\begin{array}{l}\text { During } \\
\text { pregnancy } \\
(\mathbf{N}=262)\end{array}$ & \\
\hline Domains & Mean \pm SD & Mean \pm SD & $p$-value \\
\hline Frequency & $84.9 \pm 24.2$ & $44.7 \pm 26.5$ & $<0.001$ \\
\hline Desire & $65.1 \pm 43.7$ & $51.3 \pm 25.8$ & $<0.001$ \\
\hline Arousal & $90.3 \pm 20.3$ & $53.6 \pm 36.6$ & $<0.001$ \\
\hline Orgasm & $94.1 \pm 18.9$ & $67.2 \pm 39.8$ & $<0.001$ \\
\hline Satisfaction & $93.9 \pm 14.7$ & $60.0 \pm 34.1$ & $<0.001$ \\
\hline Dyspaurenia & $88.9 \pm 31.4$ & $54.2 \pm 49.9$ & $<0.001$ \\
\hline $\begin{array}{l}\text { Intercourse } \\
\text { initiation }\end{array}$ & $94.8 \pm 15.8$ & $79.8 \pm 32.6$ & $<0.001$ \\
\hline Female difficulties & $94.3 \pm 23.3$ & $41.0 \pm 49.3$ & $<0.001$ \\
\hline $\begin{array}{l}\text { Male sexual } \\
\text { satisfaction }\end{array}$ & $93.1 \pm 18.8$ & $51.3 \pm 40.0$ & $<0.001$ \\
\hline $\begin{array}{l}\text { Male sexual } \\
\text { difficulties }\end{array}$ & $98.9 \pm 10.7$ & $89.7 \pm 30.5$ & $<0.001$ \\
\hline Composite score & $89.8 \pm 11.2$ & $59.2 \pm 22.5$ & $<0.001$ \\
\hline
\end{tabular}

Abbreviation: SD, standard deviation.

in the new classification provided in the fifth edition of the manual (DSM-V), the sexual desire and arousal disorders have been combined into one disorder, called female sexual interest/ arousal disorder, demonstrating the intimate relationship between these conditions. ${ }^{21}$ Thus, the authors believe that similar reasons would affect negatively both sexual desire and arousal. Psychologic changes, such as apprehension about pregnancy and changing lifestyle, and physical symptoms, like nausea, fatigue, exhaustion, breast tenderness, respiratory difficulties, insomnia and increased urinary frequency, could be causes of decreased sexual desire and arousal. Furthermore, structural changes in the body during pregnancy can lead some women to perceive themselves as unattractive, which also affects these sexual domains. ${ }^{16,22}$

In the domain of orgasm, we observed that the majority of women reported having orgasms both before and during pregnancy. However, there was an increase in the number of women who could not achieve orgasm during pregnancy, corroborating the findings of another study. ${ }^{15}$ Most articles, however, report only the increased difficulty in achieving orgasm, especially during the third trimester, without comparing it with pre-pregnancy findings. ${ }^{11,13,23,24}$ From the perspective of psychodynamics, the dichotomous role of mother and wife combined with cultural issues could influence sexual desire and cause difficulty in achieving orgasm, for the women might feel they are not allowed to experience this sensation during the gestational period. ${ }^{25}$

Regarding the dyspareunia domain, we observed that most of the pregnant women reported not feeling pain during sexual intercourse before pregnancy, but the majority stated that they felt pain during pregnancy, a finding also described in a prospective study ${ }^{26}$ that added that, in the postpartum period, there was a reduction in the complaints of dyspareunia compared to the gestational period. ${ }^{26}$ However, another study ${ }^{9}$ comparing pregnant and non-pregnant women regarding the pain domain, fand ound no significant differences between the groups. ${ }^{9}$ Some authors report a decrease in vagina lubrication during the gestational period, especially in the last trimester, which could justify the complaint of pain during sexual intercourse. ${ }^{9,11,26,27}$ Moreover, the decrease in sexual desire could be associated to dyspareunia, since it could also lead to a lack of lubrication.

Most participants reported that they spontaneously initiated sexual activity both before and during pregnancy. Differently from a cross-sectional Brazilian study ${ }^{12}$ that observed an increase in the initiative of pregnant women to begin the sexual act compared to the period before pregnancy. ${ }^{12}$ Data from a Turkish study ${ }^{28}$ revealed that, although both partners usually initiated pre-pregnancy sexual relations, the male partner was more likely to initiate sexual activity during pregnancy. ${ }^{28}$ On the other hand, the findings of another study conducted in Canada showed a decrease in the sexual intercourse initiative by pregnant women, which is consistent with our results. ${ }^{27}$ This discrepancy may be a result of the variation in the decrease in sexual desire and interest during pregnancy depending on the trimester studied, for example.

Evaluating the perception of the pregnant women on what would be their partners' grade on the couple's sexual life, $87.4 \%$ gave a good grade before pregnancy, while only $33.2 \%$ gave the same grade during pregnancy. These data are similar to those in the aforementioned Turkish study, ${ }^{28}$ in which, before pregnancy, none of the women believed that their husbands were dissatisfied, but, during pregnancy, $33.7 \%$ described their husbands as unsatisfied. ${ }^{28}$

A significant increase in difficulties in sexual intercourse during pregnancy was observed in the present study. Before pregnancy, $5.7 \%$ of the women presented difficulties, a rate that went up to $58.8 \%$ of women during pregnancy. A survey 29 with 207 pregnant women in Brazil found that $35.7 \%$ reported difficulties during sexual relations. The same research correlated this data with quality of life, and concluded that during pregnancy the woman is subject to suffer some alterations in her sexual life that could be related to some factors like workload and some fears and myths about sex during pregnancy, which may affect sexual intercourse. ${ }^{29}$ However, it was not possible for us to evaluate all of these factors, since the questionnaire (PSRI) used in the present study does not include these variables.

Sexual dysfunction, due to its multifactorial etiology, may have its prevalence influenced by interaction with personal variables. $^{9,20}$ In a Moroccan epidemiological study, ${ }^{30}$ low schooling was associated with sexual dysfunction. ${ }^{30}$ One might suppose that lack of education leads to lack of knowledge about female sexual anatomy and function, and the possibilities for related problem resolutions. Similarly, in the present study, we found lower rates of sexual dissatisfaction among women with higher levels of schooling; these women tend to become more independent and secure, which can reflect on sexuality.

Moreover, like the results of the previously described Moroccan study, ${ }^{30}$ in another study, ${ }^{31}$ women with four or 
more children had more sexual desire disorder than women with two children. Having one or more children had no association with increased risk of sexual dissatisfaction in the present study. The questionnaire used in by the authors did not enable a more specific analysis, and perhaps a larger sample and a greater stratification of the number of children and their ages could better clarify this association.

In the present study, most pregnant women reported that the pregnancy was not planned, which means that the pregnancy to them was somewhat of a surprise, be it positive or negative, and this generates different feelings, from feelings of intense joy and well-being to deep sadness and feeling of helplessness. ${ }^{10}$ Although pregnancy planning was not associated with sexual dissatisfaction in the present study, another Brazilian study ${ }^{12}$ described that the presence of sexual dysfunction during pregnancy was associated with unplanned pregnancies. $^{12}$

The analysis of the individual and total scores of the sexuality domains evaluated by the PSRI questionnaire suggests a negative impact of pregnancy on the response of sexual function. Although the classification of the final sexuality score during pregnancy was "good", there was a great change from the pre-pregnancy period to the pregnancy period.

Health professionals should ask pregnant women about feelings of sexual distress. Identifying pregnant women experiencing sexual difficulties and directing them to appropriate resources can help minimize sexual and relationship issues during pregnancy. ${ }^{32}$ Sexuality is capable of influencing physical and mental health, resulting in personal distress, and harming both interpersonal relationships and quality of life. Therefore, although sex often ceases to be the focus of the relationship during pregnancy, experiencing full sexuality during this period helps keep the couple together to face the many changes of that moment. ${ }^{7,26}$

Prenatal care may be an opportunity for health professionals to work in this area. The effectiveness of this type of action has already been observed in a randomized clinical trial $^{7}$ involving 88 Iranian women, in which the intervention was sexual education during pregnancy. The conclusion of the study was that providing such sexual education during routine prenatal care can improve the sexual health of couples during pregnancy. ${ }^{7}$

Understanding that sexual dysfunction may be present during pregnancy is of great importance so that some measures can be incorporated into the prenatal routine, like the investigation of sexual dysfunctions, educational measures to clarify misunderstandings, myths and doubts, and, when necessary, allowing treatments to be prescribed.

The use of a questionnaire validated specifically for pregnant women strengthens the present study, so the data obtained may be more easily compared in future studies using the same tool. Studies using questionnaires that have not been validated in the population of interest may be subject to measurement errors, and no conclusions can be drawn with confidence. ${ }^{31}$

Because this was a cross-sectional study, we can point out as a limitation the memory bias when the women were asked about the moment before pregnancy or about the previous pregnancy trimester. Another limitation was not questioning directly the male partners about their satisfaction with sexuality, once they might have had different perceptions. Since only the data in the PSRI were used, confounding factors with the level of schooling of the partner and whether the couple shares their bedroom with children, for example, could not be evaluated.

Studies with different delineations from the present one, such as a cohort, in which the women can be followed before the pregnancy, or those with a qualitative approach, which would enable the authors to record, through the narratives of the pregnant women, their experiences, beliefs and expectations, would be valuable to understand the sexuality in a broader form. Studies addressing other variables not included in PSRI could also point to other factors associated with dysfunction.

\section{Conclusion}

From these results, it is possible to conclude that the general sexual function score was good, although there was a high prevalence of female sexual dysfunctions, as the majority of pregnant women reported at least one type of alteration in the domains of sexual function, and the report of dissatisfaction was more frequent in women without high-school degrees, which highlights the importance of deepening the theme.

\section{Contributors}

Guendler JA, Katz L, Flamini MEDM, Oliveira ALB and Amorim MMR contributed to the conception and design of the present study, to the data collection or to the analysis and interpretation of data, as well as to the writing of the article or to the critical review of the intellectual content, and to the final approval of the version to be published.

Conflicts of Interest:

The authors have none to declare.

\section{References}

1 Witting K, Santtila P, Alanko K, et al. Female sexual function and its associations with number of children, pregnancy, and relationship satisfaction. J Sex Marital Ther 2008;34(02):89-106. Doi: 10.1080/00926230701636163

2 DeJudicibus MA, McCabe MP. Psychological factors and the sexuality of pregnant and postpartum women. J Sex Res 2002;39(02): 94-103. Doi: 10.1080/00224490209552128

3 Yeniel AO, Petri E. Pregnancy, childbirth, and sexual function: perceptions and facts. Int Urogynecol J Pelvic Floor Dysfunct 2014;25(01):5-14. Doi: 10.1007/s00192-013-2118-7

4 Asselmann E, Hoyer J, Wittchen HU, Martini J. Sexual problems during pregnancy and after delivery among women with and without anxiety and depressive disorders prior to pregnancy: a prospective-longitudinal study. J Sex Med 2016;13(01):95-104. Doi: $10.1016 /$ j.jsxm.2015.12.005

5 Pastore L, Owens A, Raymond C. Postpartum sexuality concerns among first-time parents from one U.S. academic hospital. J Sex Med 2007;4(01):115-123. Doi: 10.1111/j.1743-6109.2006.00379.x

6 Wolpe RE, Zomkowski K, Silva FP, Queiroz APA, Sperandio FF. Prevalence of female sexual dysfunction in Brazil: A systematic review. Eur J Obstet Gynecol Reprod Biol 2017;211:26-32. Doi: 10.1016/j.ejogrb.2017.01.018 
7 Afshar M, Mohammad-Alizadeh-Charandabi S, Merghti-Khoei ES, Yavarikia P. The effect of sex education on the sexual function of women in the first half of pregnancy: a randomized controlled trial. J Caring Sci 2012;1(04):173-181. Doi: 10.5681/jcs.2012.025

8 Ahmed MR, Madny EH, Sayed Ahmed WA. Prevalence of female sexual dysfunction during pregnancy among Egyptian women. J Obstet Gynaecol Res 2014;40(04):1023-1029. Doi: 10.1111/jog.12313

9 Prado DS, Lima RV, de Lima LM. [Impact of pregnancy on female sexual function]. Rev Bras Ginecol Obstet 2013;35(05):205-209. Doi: 10.1590/S0100-72032013000500003

10 Pauls RN, Occhino JA, Dryfhout VL. Effects of pregnancy on female sexual function and body image: a prospective study. J Sex Med 2008;5(08):1915-1922. Doi: 10.1111/j.1743-6109.2008.00884.x

11 Ylddı H. The relation between prepregnancy sexuality and sexual function during pregnancy and the postpartum period: a prospective study. J Sex Marital Ther 2015;41(01):49-59. Doi: 10.1080/0092623X.2013.811452

12 Lima AC, Dotto LMG, Mamede MV. Prevalência de disfunção sexual em primigestas, no Município de Rio Branco, Acre, Brasil. Cad Saude Publica 2013;29(08):1544-1554. Doi: 10.1590/0102-311 × 00164012

13 Rudge CVC, Calderon IMP, Dias A, et al. Design and validity of a questionnaire to assess sexuality in pregnant women. Reprod Health 2009;6:12. Doi: 10.1186/1742-4755-6-12

14 Rudge CVC, Calderon IMP, Almeida APM, Piculo F, Rudge MVC, Barbosa AMP. Score Establishment and Brazilian Portuguese version of the Pregnancy Sexual Response Inventory (PSRI). Rev Bras Ginecol Obstet 2018;40(06):322-331. Doi: 10.1055/s-00381656536

15 Malarewicz A, Szymkiewicz J, Rogala J. [Sexuality of pregnant women]. Ginekol Pol 2006;77(09):733-739

16 Eryilmaz G, Ege E, Zincir H. Factors affecting sexual life during pregnancy in eastern Turkey. Gynecol Obstet Invest 2004;57(02): 103-108. Doi: 10.1159/000075582

17 Babazadeh R, Najmabadi KM, Masomi Z. Changes in sexual desire and activity during pregnancy among women in Shahroud, Iran. Int J Gynaecol Obstet 2013;120(01):82-84. Doi: 10.1016/j.ijgo.2012.07.021

18 Ribeiro MC, Nakamura MU, Abdo CHN, Torloni MR, Scanavino MdeT, Mattar R. [Pregnancy and gestational diabetes: a prejudicial combination to female sexual function?] Rev Bras Ginecol Obstet 2011;33(05):219-224. Doi: 10.1590/S0100-7203201100 0500003

19 Tugut N, Golbasi Z, Bulbul T. Quality of sexual life and changes occurring in sexual life of women with high-risk pregnancy. J Sex Marital Ther 2017;43(02):132-141. Doi: 10.1080/0092623X. 2016.1141816
20 Kahramanoglu I, Baktiroglu M, Hamzaoglu K, Kahramanoglu O, Verit FF, Yucel $\mathrm{O}$. The impact of mode of delivery on the sexual function of primiparous women: a prospective study. Arch Gynecol Obstet 2017;295(04):907-916. Doi: 10.1007/s00404-017-4299-7

21 Latif EZ, Diamond MP. Arriving at the diagnosis of female sexual dysfunction. Fertil Steril 2013;100(04):898-904. Doi: 10.1016/j. fertnstert.2013.08.006

22 von Sydow K. Sexuality during pregnancy and after childbirth: a metacontent analysis of 59 studies. J Psychosom Res 1999;47(01): 27-49. Doi: 10.1016/S0022-3999(98)00106-8

23 Aydin M, Cayonu N, Kadihasanoglu M, Irkilata L, Atilla MK, Kendirci M. Comparison of sexual functions in pregnant and non-pregnant women. Urol J 2015;12(05):2339-2344. Doi: 10.22037/uj.v12i5.2881

24 Bartellas E, Crane JM, Daley M, Bennett KA, Hutchens D. Sexuality and sexual activity in pregnancy. BJOG 2000;107(08):964-968. Doi: 10.1111/j.1471-0528.2000.tb10397.x

25 Camacho KG, Vargens OMC, Progianti JM. Adaptando-se à nova realidade: a mulher grávida e o exercício de sua sexualidade. Rev Enferm UERJ. 2010;18(01):32-37

26 Gökyildiz S, Beji NK. The effects of pregnancy on sexual life. J Sex Marital Ther 2005;31(03):201-215. Doi: 10.1080/0092623059 0513410

27 Vannier SA, Rosen NO. Sexual distress and sexual problems during pregnancy: associations with sexual and relationship satisfaction. J Sex Med 2017;14(03):387-395. Doi: 10.1016/j.jsxm.2016.12.239

28 Corbacioglu Esmer A, Akca A, Akbayir O, Goksedef BPC, Bakir VL. Female sexual function and associated factors during pregnancy. J Obstet Gynaecol Res 2013;39(06):1165-1172. Doi: 10.1111/ jog. 12048

29 Bezerra IFD, de Sousa VP, dos Santos LC, Viana EdeS. [Comparison of quality of life in women with sexual dysfunction]. Rev Bras Ginecol Obstet 2015;37(06):266-271. Doi: 10.1590/SO100720320150005254

30 Kadri N, McHichi Alami KH, McHakra Tahiri S. Sexual dysfunction in women: population based epidemiological study. Arch Women Ment Health 2002;5(02):59-63. Doi: 10.1007/s00737-002-0141-7

31 Dowrick AS, Wootten AC, Murphy DG, Costello AJ. We used a validated questionnaire: what does this mean and is it an accurate statement in urologic research? Urology 2015;85(06):1304-1310. Doi: 10.1016/j.urology.2015.01.046

32 Olsson A, Lundqvist M, Faxelid E, Nissen E. Women's thoughts about sexual life after childbirth: focus group discussions with women after childbirth. Scand J Caring Sci 2005;19(04):381-387. Doi: 10.1111/j.1471-6712.2005.00357.x 